Hydrology and Earth System Sciences, 9, 507-515, 2005

www.copernicus.org/EGU/hess/hess/9/507/

SRef-ID: 1607-7938/hess/2005-9-507

European Geosciences Union

\title{
Resolving conflicting objectives in the management of the Plastiras Lake: can we quantify beauty?
}

\author{
A. Christofides, A. Efstratiadis, D. Koutsoyiannis, G.-F. Sargentis, and K. Hadjibiros \\ National Technical University of Athens, Greece \\ Received: 23 March 2005 - Published in Hydrology and Earth System Sciences Discussions: 30 May 2005 \\ Revised: 26 September 2005 - Accepted: 4 October 2005 - Published: 19 October 2005
}

\begin{abstract}
The possible water management of the Plastiras Lake, an artificial reservoir in central Greece, is examined. The lake and surrounding landscape are aesthetically degraded when the water level drops, and the requirement of maintaining a high quality of the scenery constitutes one of the several conflicting water uses, the other ones being irrigation, water supply, and power production. This environmental water use, and, to a lesser extent, the requirement for adequate water quality, results in constraining the annual release. Thus, the allowed fluctuation of reservoir stage is not defined by the physical and technical characteristics of the reservoir, but by a multi-criteria decision, the three criteria being maximising water release, ensuring adequate water quality, and maintaining a high quality of the natural landscape. Each of these criteria is analyzed separately. The results are then put together in a multicriterion tableau, which helps understand the implications of the possible alternative decisions. Several conflict resolution methods are overviewed, namely willingness to pay, hedonic prices, and multi-criteria decision analysis. All these methods attempt to quantify non-quantifiable qualities, and it is concluded that they don't necessarily offer any advantage over merely making a choice based on understanding.
\end{abstract}

\section{Introduction}

Reservoir management normally has to take into account several conflicting objectives. This paper explores the case of the Plastiras Lake, a reservoir whose purpose changed to a significant extent since it was built, and whose conflicting objectives include scenery.

The Plastiras Lake (Fig. 1, Table 1) was built in central Greece toward the end of the 1950s mainly for power pro-

Correspondence to: A. Christofides

(anthony@itia.ntua.gr) duction, and was also used for irrigation of a significant part of the plain of Thessaly. By making the land more fertile, it contributed to an increase in the population and income of the nearby city of Karditsa. As the economy of Karditsa became dependent on the water of the reservoir, the social and political pressure gradually shifted the reservoir's main objective; by 1990 it was the irrigation needs that dictated water management, reducing power production to a side-effect, and halving the economic value of the $160 \mathrm{GWh}$ produced annually, as a result of the water release not following an energy-efficient schedule. Meanwhile the scenery, combined with the geographical accessibility of the lake, attracted visitors. During the 1990s, a number of villages around the lake, which had almost been deserted since 1980, were revived as tourist resorts. The level of water in the lake greatly affects its appearance, and this resulted in pressures to keep the level high. Furthermore, the water of the lake started to be used for the water supply of Karditsa and other areas, stressing the need for high water quality.

The project involves water diversion from a wet river basin (Acheloos) to a drier one (Peneios), where different groups of stakeholders with different interests are influenced by the reservoir management. Due to the major importance of the project, and the involvement of more than one local government bodies, until now decisions are taken at a national level, by a committee from the Ministry of Development, the Ministry of Agriculture and the Public Power Corporation. Local authorities, such as the Municipality of Karditsa, the Prefectural Government of Karditsa, the District Government of Thessaly, as well as farmer unions and other related municipalities, influence decisions indirectly. The operation of the reservoir according to the decisions taken is done by the Public Power Corporation, under the guidance of the District Government of Thessaly. The study outlined below was solicitied by some of these bodies, in order to propose an optimal management policy. Although the study includes details about releases, the primary aim was to define a minimum

(C) 2005 Author(s). This work is licensed under a Creative Commons License. 
Table 1. Characteristics of the lake and its basin.

\begin{tabular}{ll}
\hline Basin area & $161.3 \mathrm{~km}^{2}$ \\
Highest basin altitude & $2140 \mathrm{~m}$ \\
Maximum design lake level & $794 \mathrm{~m}$ \\
Spill level & $792 \mathrm{~m}$ \\
Minimum release level & $776 \mathrm{~m}$ \\
Lake area at spill level & $25 \mathrm{~km}^{2}$ \\
Lake area at minimum release level & $15 \mathrm{~km}^{2}$ \\
Mean annual inflow & $153 \mathrm{hm}^{3}$ \\
Mean annual inflow depth & $1029 \mathrm{~mm}$ \\
\hline
\end{tabular}

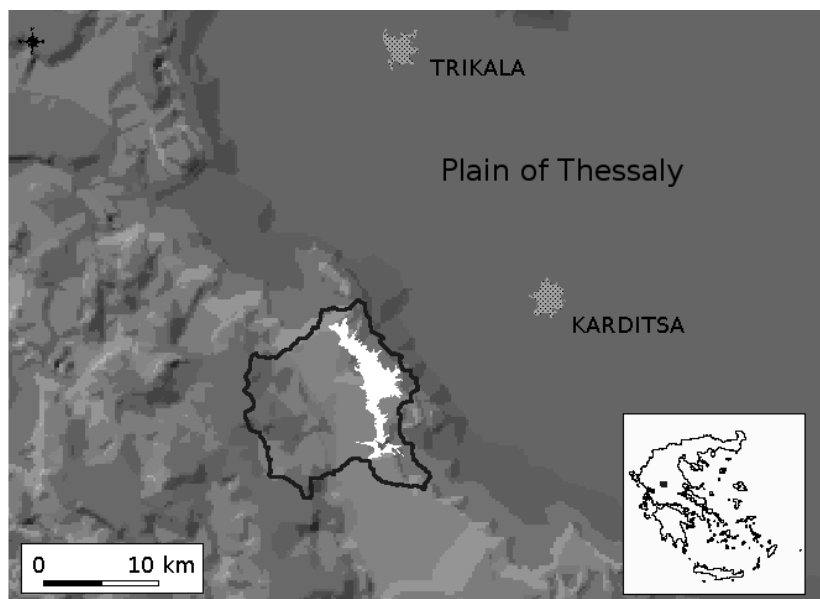

Fig. 1. The Plastiras Lake and its surroundings. The lake is shown in white, the dark line indicating the watershed. The spot on the small map of Greece indicates the position of the watershed.

allowed lake level. This has the advantage that it is a single numeric value easy to grasp, to incorporate in regulations, and to verify compliance with.

The scenery is rarely mentioned as a kind of water use in reservoir management. Similar uses are recreation, tourism, and environmental. We would classify the requirement to have beautiful scenery as both environmental and tourist water use, not in the traditional sense that associates it with water sports, but rather in the sense of the rapidly growing segment of ecotourism (Neto, 2003).

The next section presents various alternative widely used decision making methods and discusses their shortcomings, whereas the case study of the Plastiras Lake is developed in the rest of the paper. Specifically, the essential principles that have led to the formulation of the problem are discussed in Sect. 3; the next three sections describe, respectively, the hydrological simulation, the water quality study, and the scenery study. Sect. 7 explains the decision-making strategy and presents the proposal made. Section 8 presents an alternative approach, based on multicriteria decision-making. Finally, Sect.9 summarizes the conclusions and provides some proposals for further discussion.

\section{Decision-making under conflicting objectives: an overview}

In water management studies, where decisions must simultaneously satisfy several conflicting objectives, methods based on benefit-cost analysis or multicriteria decision analysis are frequently used to help identify the "optimal" decision. In this section we shortly review these methods and discuss their shortcomings.

Classical decision theory states that rational decisions are those that maximize some utility function (Wierzbicki, 1997). One common way to construct such a function is to use benefit-cost analysis, that is, translate all criteria into monetary values. For some criteria, such as available water quantity, this is straightforward; but it is very hard to measure scenery quality in monetary units. A common method of doing so is to make surveys and use the people's willingness to pay (WTP) as the supposed monetary value of scenery quality. There is, however, important criticism on this approach. Wenstøp and Seip (2001) mention several studies which cause serious doubts about any validity in WTP. "These surveys only bring forward unreflective prejudices of people, most of [whom] are not well equipped to make decisions about these matters, because they have never taken part in any relevant public inquiry and deliberation" (Arler, 2000). There are also ethical objections: "For example, market mechanisms do not supply incentives for sustainable harvesting in an 'open access' economy; it does not protect species that have growth rates much less than current interest rates ... and it does not provide categorical exclusions from use of, for example, natural wonders" (Wenstøp and Seip, 2001).

An alternative method of benefit-cost analysis is the hedonic price method or HPM (Rosen, 1974), in which the prices of similar marketable goods, such as similar houses, are compared in order to identify differences that can reasonably be attributed to the presence of a non-marketable good such as silence, the basic idea being that, if all other factors could be assumed to be equal, the price difference would be an indicator of the cost of the non-marketable good. Loomis and Feldman (2003) use this method in a study of Lake Almanor, California, similar to that of Lake Plastiras. They examine the prices at which houses around the lake have been sold and they correlate them to the level of the lake at the time of sale. Although the use of HPM is interesting, it is questionable whether it is really possible to make all other factors equal. Loomis and Feldman assume that the price of a house is a linear function of twelve items (number of bathrooms, building size, distance from the lake, garage, etc.), the twelfth being the length of exposed shore. Even if we discard the fact that assuming a linear function is already a simplification, the function is still too complex to be of value, and the results have marginal statistical significance.

Given the problems of benefit-cost analysis, some prefer multi-criteria decision analysis (MCDA), in which the utility 
function is usually approximated by the weighted sum of the scores of the criteria. Of course, the scoring and the selection of weights are, to a certain extent, arbitrary. Proponents claim that such decisions cannot be objective, that this arbitrariness reflects the subjective preferences of the decision, and that MCDA is valuable because it makes the subjectivity explicit rather than present the decision as a black box (Bonte et al., 1998).

Several schools of criticism, however, have challenged the fundamental assumption of mainstream decision theory that a rational decision maximizes some kind of utility function. Wierzbicki (1997) provides an overview of these schools, the most extreme of which, well represented by Dreyfus and Dreyfus (1986), claims that decisions are mostly intuitive, because the complexity of the problems does not allow them to be tackled by analytical theory. "Ask any great athlete, or artist, or charismatic leader - ask any great decision maker. All of them describe a similar process, in which analytical and rational means are used extensively both in preparation for and in review of a central moment of performance. But in the moment itself, the actual decisions are made intuitively" (Moore, 1999). "The spontaneous, speedy and effortless way in which intuitive thinking allows the nub of a problem to be grasped is possible because of the non-conscious use of a non-linear reasoning process. The intuiter perceives the situation in a holistic way because of his or her deep involvement in the problem" (Easen and Wilcockson, 1996). Wierzbicki (1997) argues that language was one of the last features to appear in the evolution of humans, and thus that for solving many problems other, older abilities of the brain may be more appropriate: "our minds work also on a deeper layer of nonverbal image processing — which task employs a large part of the mind's processing potential, is sometimes conscious but often subconscious and uses rather multivalued than binary logic." Dreyfus and Dreyfus (1986) criticize western society of overemphasizing analytical thought, and of dismissing, as irrational, thought processes whose results cannot be analytically explained. "Against such a yard-stick, intuitive thinking is considered to be both inferior and unprofessional" (Easen and Wilcockson, 1996).

Through the study of Lake Plastiras, presented in the next sections, new issues on environmental water resource management are revealed, whereas the drawbacks of conventional multicriteria analysis methods are further highlighted.

\section{Problem statement}

Natural inflows vary irregularly in all temporal scales, including annual and multi-annual scales. The purpose of a reservoir is to regulate inflows and provide outflows at a more regular rate, which is determined by water demand, temporarily storing the surplus, when inflows exceed outflows. The reservoir under study has been designed to perform multi-year regulation with a constant annual release.
Although in many cases (e.g. Agrell et al., 1998) the practice followed is releasing a variable quantity of water each year, depending on the amount of water in the reservoir, the adoption of a constant annual release instead, irrespective of the amount of water available, is beneficial: the various waterdependent activities can be scheduled more efficiently, since a specific quantity of water is guaranteed, albeit with a certain probability of failure, to be available each year.

Reservoir design and management is often based on a non-probabilistic basis, which assumes a failure-free concept such as the "firm yield". However, any target release normally has a nonzero probability of failure, and it is more accurate to study the reservoir on a probabilistic basis and talk about "reliable release" rather than firm yield (Koutsoyiannis, 2004); the reliable release is the amount of water that can be provided with a specified reliability level or probability of failure. Thus, if the annual release with $90 \%$ reliability is $300 \mathrm{hm}^{3}$, this means that, on the average, once in a decade the actual release will be less than $300 \mathrm{hm}^{3}$.

The reliable annual release is a function of the hydrologic regime of the basin, the reliability level, and the net reservoir capacity. For the Plastiras Lake, the net reservoir capacity is defined by specifying the minimum allowed level (see the storage function in Fig. 2). Our decision-making alternatives are expressed by means of minimum allowed level for abstractions from the lake, because minimum lake level is a simple notion, easy to incorporate into regulations, and easy to verify. The decision space is continuous; any real value between $+776 \mathrm{~m}$ (intake elevation) and $+792 \mathrm{~m}$ above sea level (spillway crest elevation) can, in theory, be chosen. However, in the latter stages of our analysis, we limited our selection to one of the five values of $+780,+782,+784,+786$ and $+788 \mathrm{~m}$.

In summary, the problem is to select one of the five options for minimum allowed level mentioned above by arranging the three conflicting objectives of maximising water release, ensuring adequate water quality, and maintaining a high quality of scenery, subject to the following assumptions:

- Constant annual release. Except for the especially dry periods, as mentioned below, the same quantity of water will be taken from the lake, irrespective of the water available.

- 90\% reliability. The annual yield mentioned in the table will be released in $90 \%$ of the cases. Once in ten years (on average) it will not be possible to release this quantity without violating the minimum allowed level.

- Maintain level rather than release in failures. When the system fails, the minimum allowed level will not be violated; instead, the release will be reduced.

- Priority of water supply and irrigation versus power production. The current practice, in which irrigation is the water use that dictates the operation of the reservoir, 


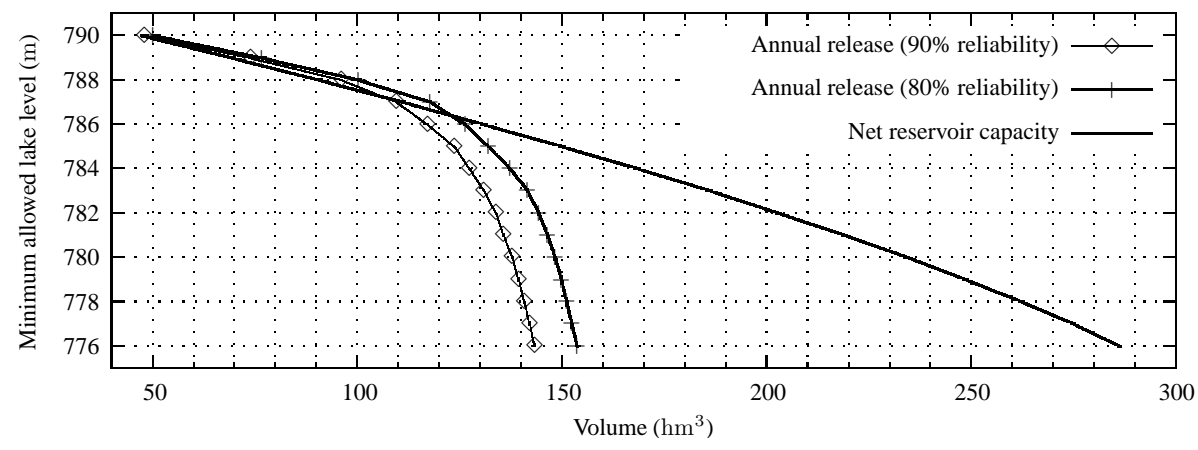

Fig. 2. Reliable yield as a function of minimum level.

is assumed to continue in the future to avoid social reactions. Thus, the annual release is distributed nonuniformly throughout the year as required by the water supply and irrigation water uses.

We strongly emphasize that although the minimum level stands as the key issue of the management problem, the reservoir operation is implemented on the basis of a constant annual release, which ensures both the maintenance of the aforementioned level and the specified reliability, irrespectively of the quantity of hydrological inflows. Hence, even if the actual level is much higher than the allowable limit, the annual release must never exceed its target value (as specified through the hydrological analysis).

\section{Reliable release as a function of minimum level}

The relationship between the minimum abstraction level and the maximised annual release was established by coupling three modelling components: (a) a stochastic simulation scheme; (b) a reservoir operation model; and (c) a multiobjective optimisation framework.

Initially, historical records of upstream runoff (based on the water balance of the lake), rainfall and evaporation (based on the Penman method) were constructed, on a monthly basis. Next, synthetic series of 1000 years length were generated, by employing a multivariate stochastic hydrology scheme that reproduces the statistical characteristics of the historical records, as well as the Hurst phenomenon (Koutsoyiannis, 2000). These are inputs to the reservoir operation model, which is a typical simulation scheme that calculates the annual safe release, for given reservoir properties (e.g. capacity), given inflows (either historical or synthetic) and given reliability level. The details of the process are outside the scope of the paper; for more information, the reader is referred to related literature (Pegram, 1980; Loucks et al., 1981; Mays and Tung, 1996; ReVelle, 1999; Koutsoyiannis, 2004). Finally, an optimisation problem was formulated, by assuming the reliable release as the objective function to maximise and constraining the allowable abstraction level to a specific value. By solving the problem for different level scenarios within the corresponding feasible range (i.e. $+776 \mathrm{~m}$ to $+790 \mathrm{~m}$ ), alternative management options were obtained, as shown in Fig. 2.

Using a systems-analysis terminology, the curve in Fig. 2 illustrating the reliable release versus the minimum abstraction level stands as the Pareto front of a multiobjective optimisation problem, whereas the adopted methodology is identical to the $\mu$-constraint technique for generating non-inferior solutions (Cohon, 1978, p. 115). On the absence of further information, all points lying on the curve correspond to equivalently acceptable reservoir operation policies. Besides, the entire region on the left of the curve corresponds to sub-optimal policies, whereas the region on the right corresponds to infeasible policies. The introduction of water quality and scenery quality criteria helped to further constraint the acceptable policies till resulting to a "best-compromise" one, as explained in the next sections.

\section{Water quality}

The effect of lake level variation on water quality was assessed with the aid of two models, which are described by Stamou et al. (1994), Hadjibiros et al. (2002) and Andreadakis et al. (2003). Both models simulate various physical, chemical and biological processes of a reservoir, emphasising on eutrophism and oxygen. The same assumptions about polluting loads were made for both models, and the same input data were used. The output of the hydrologic simulation outlined in the previous section was used as water level variation scenarios. The polluting loads were estimated on the basis of land use in the basin, both nonpoint (mainly agriculture and animal husbandry) and point sources (sewerage of residential locations). Both models were calibrated on a small number of chlorophyl concentration measurements.

Despite their different methodological background, both approaches agree that the lake is generally oligotrophic. However, if the minimum allowed level is set at $+782 \mathrm{~m}$, the chlorophyll concentration during summer is as high as tending the lake to the limit of the mosotrophic state, whereas if 
it set at $+780 \mathrm{~m}$, the lake is well in the mesotrophic state. During visits to the lake it was also noted that at levels below $+782 \mathrm{~m}$ the water begins to have an unpleasant odour.

\section{The scenery}

When the lake is full, that is, when it is at its highest level of $792 \mathrm{~m}$, the trees appear to touch the water. Although there is a sharp contrast of mountains that seem to spring out of water, the observer has the impression that the landscape is unified and pure. When the level of the lake drops, a piece of land is revealed between the trees and the water, and this affects the unity of the landscape. At the north part of the lake, where the slopes are small, large dry areas appear; at the south, where the landscape is rugged, a brown or yellowish narrow strip shows. This phenomenon, which is illustrated in Fig. 3, is not prominent for levels of $787 \mathrm{~m}$ or more, because many trees grow from levels of 790-791 m, and they cast their shadows even lower.

Such lifeless areas marking the transition from land to water are common in nature; a sand beach in front of a forest is a typical example. The reason for their existence is that the ecosystem developed on the boundaries of water and land is very sensitive (Nebel and Wright, 1981, p. 28). Transition areas also appear in natural lakes, even if there is no significant exploitation of the water, due to the natural variation of inflow. However, natural transition areas are very different. First, nature creates gradual transitions; for example, immediately after the sand beach there is usually low foliage, and the trees are farther away. Second, in most cases, natural shores either are rocky (as are, for example, fiords) or their slopes are gentle, since the water, during the course of the millenia, smooths the earth down. By contrast, artificial lakes, which are only up to some decades old, can have rugged clay shores; this uncommon element is an asset, and it is one of the things that has made the Plastiras lake wellknown; but it has the downside that it results in prominent transition areas of exceptionally regular geometry, as can be seen in the lower left photograph of Fig. 3. Finally, the surface of the transition area leaves a bad impression of unnatural texture. Some decades ago it was forest; some months or years ago it was submerged; but now it has neither forest nor water, and it seems lifeless. In addition, the transition area makes the lake appear empty, because it reveals the lake's potential area and volume and provides the observer with a means of comparison.

Talks with the local people and visitors, and questionnaires, showed that people who live at the lake or visit it regularly notice the degradation of the scenery much more than new visitors. Table 2 shows a classification of scenery based mostly on the survey of opinions. This classification, especially in the level of detail in which it is presented, is only an indication, and is, to some extent, arbitrary; aesthetic quality is neither measurable nor objective, and there are no

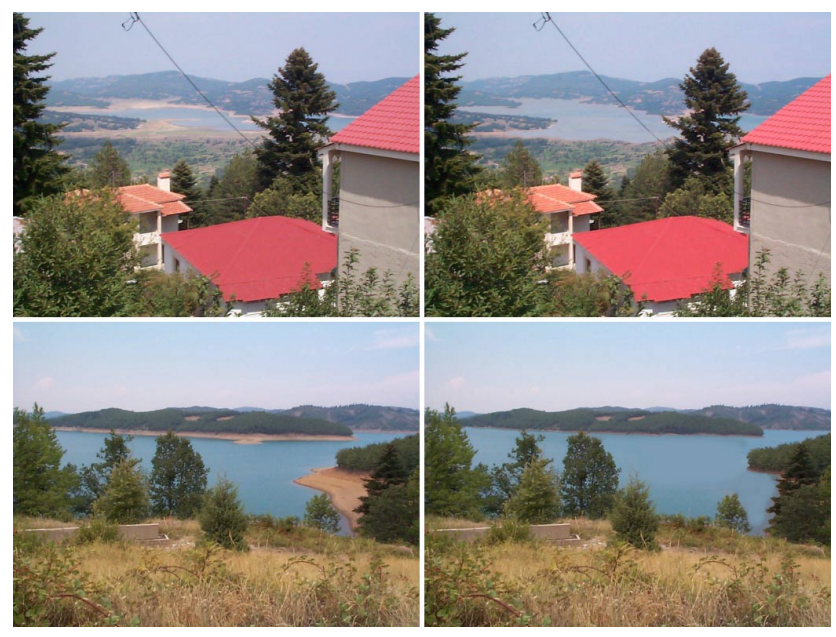

Fig. 3. The transition area. The photographs on the left have been taken on the north and south part of the lake when its level was $781.3 \mathrm{~m}$. On the right the same photographs are digitally processed to show how the landscape would be if the lake were full.

clear division lines. However, Table 2 provides a necessary measure for the arrangement of conflicting objectives.

In order to refine our opinion and appreciation of the scenery, we observed and photographed the lake from different locations and altitudes, in different seasons, and for different lake levels. In addition, we analysed the landscape from several viewpoints: specifically, by identifying its dominant form, lines, colours and texture; examining the essential aesthetic factors, namely contrast, gradualness, convergence, balance, axes; identifying variable factors, such as observing location and distance, and movement; investigating psychological associations and symbolisms, such as whether the landscape appears to be fair, honest, useful, respectful, holy, and communicative; studying its orientation, sights, and its degree of surprise, uniqueness, and variety; and by assessing its ability to optically absorb human-incurred alterations. These techniques are described in more detail by Sargentis et al. (2005), Hadjistathis and Ispikoudis (1995), and Stefanou (2001).

All this analysis appears at first to contradict our belief that there is little objectivity in aesthetics. If I like something, then I like it; this needs no justification, and there is very little that analysis can do in order to change my mind or enforce my opinion. However, all the aforementioned analysis helps to learn the landscape, to get acquainted with its details, and to get the bigger picture, so that afterwards we are more confident when we just look at the lake and say "I like it more today than a month ago" or "I find the landscape impressive and powerful at the south, but more relaxing at the west". In addition, the analysis is a form of self observation, which leads us to understand some of the reasons underlying our liking or not liking, and thus enabling us to predict whether other people might also agree or disagree with us. 
Table 2. Classification of scenery by lake level.

\begin{tabular}{|c|c|c|}
\hline Level (m) & Quality & Remarks \\
\hline $788-792$ & Excellent & The transition area is almost (788-790) or totally (790-792) absent. \\
\hline $786-788$ & Very good & The transition area is barely perceived and the scenery appears slightly affected. \\
\hline $784-786$ & Good & $\begin{array}{l}\text { The transition area is clearly visible. The scenery is considerably affected, but } \\
\text { is still satisfactory. }\end{array}$ \\
\hline $782-784$ & Fair & The scenery is significantly affected, and it only just satisfies observers. \\
\hline $776-782$ & Bad & The scenery is seriously degraded and the lake seems empty to most observers. \\
\hline
\end{tabular}

\section{The decision}

The problem is summarised in Table 3, a multicriterion tableau (Hipel, 1992), where we describe criteria against alternatives for the five characteristic level values. Under a systems approach, if a fitness value could be assigned to each criterion, then the alternatives would correspond to characteristic points of a curve lying on a 3-D objective space, i.e. the Pareto front of the relating multiobjective optimisation problem (in reality, the middle part of it, which contains the most promising alternatives). Although the Pareto front provides useful information regarding trade-offs between the conflicting criteria, a tabular representation of it, especially in problems with more than two criteria, is more practical regarding the decision-making process, since the table may contain additional information instead of pure (and sometimes arbitrary) numerical values.

The irrigation period for cotton, which is the main product produced in the plain, lasts from around April to September. The months with the largest rainfall are November and December, and inflows are still large in March, partly because of melting snow. The irrigation period is dry. The balance is generally negative during the irrigation period and positive during the rest of the year. As a result, the level in the lake is highest around late March, and lowest by the end of the irrigation period (i.e. September).

A useful output of the reservoir operation study were the frequency achieving the characteristic levels, as indicated in Table 3; these frequencies, expressed on a monthly basis, were empirically evaluated by accounting for the percentage of time steps the level is above each limit. For example, if we set the minimum allowed lake level at $+780 \mathrm{~m}$, then $7 \%$ of the time (i.e. slightly less than one month per year), the scenery will be "bad" (level less than $+782 \mathrm{~m}$ ). This may not necessarily be the same month each year, but a series of months during some dry period, whereas during wet years the reservoir level will remain higher than $+782 \mathrm{~m}$.

Table 3 shows that it doesn't make much sense to make a choice of less than +782 m or more than $+786 \mathrm{~m}$. If, for example, we choose $+780 \mathrm{~m}$, we gain only $4 \mathrm{hm}^{3}$ annually in comparison to $+782 \mathrm{~m}$, whereas the deterioration both in the scenery and in the quality of water is significant. At the other extreme, preferring +788 over +786 m causes a small improvement in scenery and quality, at the cost of more than $20 \mathrm{hm}^{3}$ annually. This is also illustrated in Fig. 2, where the $90 \%$ reliability line has a mild slope between levels +782 and $+787 \mathrm{~m}$.

The level of $+782 \mathrm{~m}$ is particularly attractive. It provides a reasonably large annual quantity, fair quality, and scenery that is at least "very good" for around $80 \%$ of the time. Whether the remaining $20 \%$ is acceptable is debatable. According to one reasoning, it is even welcome; given the unpredictability of nature, it would be dishonest and unnatural if at the end of two particularly dry years the lake did not appear empty, even more so given that Greece is a dry country. An empty lake at the end of a dry period is natural and symbolises the life-giving importance of the lake, whose water supplies Karditsa, irrigates the cotton, and produces power. In addition, the contrast between different levels may cause the scenery to be appreciated more.

Whether the $20 \%$ of inferior scenery is acceptable or not, there is an additional problem. As mentioned in Sect. 3, the study assumes a constant annual release, irrespective of the amount of water in the lake (except whenever there is a failure). The farming population is likely to have difficulty in understanding this concept or agree with its justification, and put pressure in order to release more water in wet years, on the reasonable, but suboptimal, grounds of why not draw more since the lake is full. Local politicians may also second this pressure, given that they frequently plan only up to the next voting, which may be long before the results of overdrawing become apparent. Possible submission to such pressures may result in a change in the policy, from "constant annual release" to "as much as possible but not below minimum level", a practice which, besides being detrimental to good planning, would mean that the level would be close to the minimum level for longer than planned. Such a fear warrants an increase of the minimum level to $+784 \mathrm{~m}$, or even to $+786 \mathrm{~m}$.

Based on all this reasoning, a minimum level of $+786 \mathrm{~m}$ was characterised as "desirable", while a level of $+784 \mathrm{~m}$ was characterised as "minimum acceptable". The decision about how much water to draw must be taken by the authorities each year in late March (just before irrigation period begins). 
Table 3. Multicriterion tableau for deciding the minimum lake level.

\begin{tabular}{|c|c|c|c|c|}
\hline Min level & $\begin{array}{l}\text { Reliable annual } \\
\text { yield }\left(\mathrm{hm}^{3}\right)^{*}\end{array}$ & \multicolumn{2}{|c|}{$\begin{array}{l}\text { Time distribution for } \\
\text { scenery quality }\end{array}$} & $\begin{array}{l}\text { Mean summer } \\
\text { chlorophyll- } \alpha \text { concen- }\end{array}$ \\
\hline$+780 \mathrm{~m}$ & $137.9(+10.4)$ & $\begin{array}{r}7 \% \\
8 \% \\
12 \% \\
27 \% \\
46 \%\end{array}$ & $\begin{array}{l}\text { Bad } \\
\text { Fair } \\
\text { Good } \\
\text { Very good } \\
\text { Excellent }\end{array}$ & 5.6 \\
\hline$+782 \mathrm{~m}$ & $134.0(+6.5)$ & $\begin{array}{r}8 \% \\
11 \% \\
28 \% \\
53 \%\end{array}$ & $\begin{array}{l}\text { Fair } \\
\text { Good } \\
\text { Very good } \\
\text { Excellent }\end{array}$ & 3.9 \\
\hline$+784 \mathrm{~m}$ & 127.5 & $\begin{array}{l}10 \% \\
29 \% \\
61 \%\end{array}$ & $\begin{array}{l}\text { Good } \\
\text { Very good } \\
\text { Excellent }\end{array}$ & 3.6 \\
\hline$+786 \mathrm{~m}$ & $117.3(-10.2)$ & $\begin{array}{l}26 \% \\
74 \%\end{array}$ & $\begin{array}{l}\text { Very good } \\
\text { Excellent }\end{array}$ & 3.1 \\
\hline$+788 \mathrm{~m}$ & $96.3(-31.2)$ & $100 \%$ & Excellent & \\
\hline
\end{tabular}

* The value shown in brackets is the quantity of water gained annually with reference to $+784 \mathrm{~m}$.

Normally (in 9 out of 10 years on the average) this will be the amount indicated on Table $3\left(+127.5 \mathrm{hm}^{3}\right.$ for the "minimum acceptable" choice, or $+117.3 \mathrm{hm}^{3}$ for the "desirable" choice). Whenever the system fails, the net quantity available should be drawn instead.

\section{Alternative decision making methods}

For completeness of the study, we attempted to apply the classical decision methods described in Sect. 2 and compare them with the results of Sect. 7. For WTP and HPM only few data existed from an earlier study (Sargentis, 1998), which were not sufficient to support their application. Thus only the typical MCDA approach was possible. This was implemented by formulating a utility function, where the three criteria of Table 3 are aggregated in a single numerical expression. For each criterion we assigned a dimensionless performance measure $f(z)$ as a function of minimum allowable level $z$; the value of 1 corresponds to the best case whilst the value of 0 corresponds to the worst one. The procedure for the annual safe release criterion was straightforward, whereas for the other two criteria we made some arbitrary and, necessarily, simplifying assumptions. Specifically, for the water quality criterion we constructed a dimensionless trade-off curve by interpolating on the chlorophyll concentration values of Table 3 , whereas for the scenery criterion

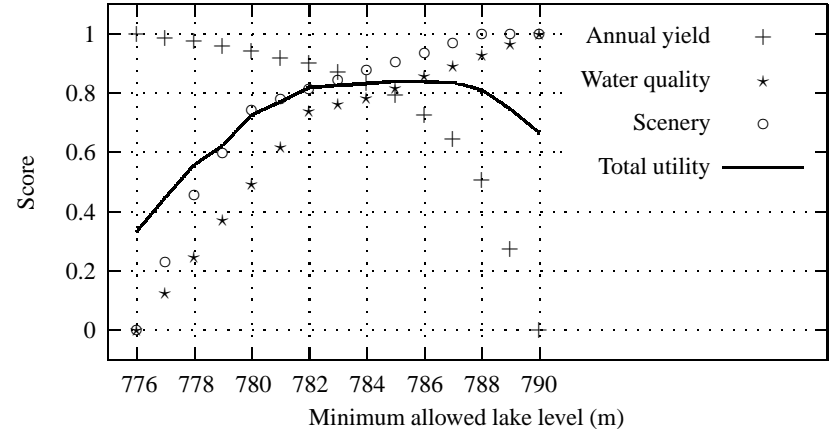

Fig. 4. MCDA example on Plastiras Lake.

we introduced a fuzzy score function, combining the four frequency values that are mentioned above.

The graphical representation of the utility function versus the minimum level, assuming equal unit weights for the three criteria, is illustrated in Fig. 4. It is evident that the multiobjective approach does not improve the comprehension of the problem, since an extended range of alternative options is obtained $(+782 \mathrm{~m}$ to $+787 \mathrm{~m})$, which provide almost equal utility. A sensitivity analysis on the weighting factors indicated that the form of this function does not vary significantly, whereas the theoretically optimal value is uncontrollably shifting within the aforementioned range. Hence, the multicriteria approach seems to do nothing more than 
confirm our intuition about reasonable operation policy options. However, it is likely that it does so because of our intuitive selection of scoring and weights, and one could argue, as Dreyfus and Dreyfus (1986, p. 162) do, that "what passes for science is really managerial art. It seems a pity that a subterfuge such as this is necessary." Another problem is that MCDA does not account for additional factors like those mentioned in Sect. 7, and although we could define more criteria like "honesty of landscape", "tolerance of bad resource management", "water clarity", "odour", and so on, and introduce them in the utility function, we don't see in what way this could contribute either to our understanding of the problem, or to communication of such understanding to the stakeholders.

\section{Conclusions and discussion}

The water management problem encountered is a challenging and original case. Through the study, interesting issues are raised, such as: (a) the change of purpose for a large hydraulic project, as traditional water uses (e.g. hydropower, irrigation) are given less importance in favour of new ones (e.g. recreation, ecotourism); (b) the fact that, in opposite to the mainstream concept about the economic usefulness of reservoirs and their negative impacts on the environment, such a project, under the condition of a rational management, improves the environmental quality and becomes attractive for new investments, thus contributing significantly to the development of the neighbouring regions; and (c) the incorporation of a new criterion regarding reservoir management, which is the aesthetics of the scenery around the lake. Although it is rather impossible to develop a generalised environmental indicator to measure the beauty of landscape, in our study the latter was taken into account using tools such as questionnaires and measures such as the time-distribution of reservoir level; both approaches are trivial to implement and easily understandable by decision-makers and stakeholders.

Since the delivery of the study in early 2002, the local authorities have followed our proposals closely for the first two irrigation periods, but violated them slightly in the third period and greatly in the current year (the abstractions significantly surpassed the target value and the current level is now below the minimum acceptable level of $+784 \mathrm{~m}$ ). Fears about not following the constant annual release principle have been proven to be justified, thus indicating the difficulty of convincing the public about the value of adopting environmental criteria in water resources management. Hence, the gap between scientific reasoning and decision making on the one hand and powerful stakeholders on the other (in this case farmers influencing politicians) remains large, although this study found positive comments within the local community. However, after this year's violations, stakeholder groups supporting ecotourism have reacted, giving hope that the proposal made may eventually survive. In this respect, there is a movement in local authorities to grant the proposal legal status at national level, so that its violation will be an illegal act.

Regarding the decision-making process towards forming our proposal, we found traditional approaches, based on quantitative methods such as MCDA, of little practical benefit. We believe that in case of complex problems, where multiple, non-measurable criteria must be taken into account, human experience and intuition is necessary to compromise the conflicting objectives. This does not mean that we are against "reason". Unfortunately the dichotomy of "rationality vs. intuition" and "rationality vs. holistic understanding" seems to imply that intuition and holistic understanding are somehow irrational; however the definition of rationality in traditional economic sense, such as "complete and transitive preferences" (Mas-Colell et al., 1995, p. 6), has little to do with the everyday use of the word, where it is synonymous with "reasonableness". We think that extensive analysis of the problem from several viewpoints, and a presentation of the reasoning such as the argumentation of Sect. 7, is what is needed to achieve an informed decision based on understanding. While it is true that choosing one solution from the range of 782-786 $\mathrm{m}$ is entirely subjective (in fact, while debating this, the opinions heard covered the whole range), it is doubtful whether utility maximisation methods can do better. This, however, is a philosophical argument that has been going on for some time.

Acknowledgements. The research of this paper was performed within the framework of the project "Investigation of scenarios for the management and protection of the quality of the Plastiras Lake," funded by the Prefectural Government of Karditsa and the Municipality of Karditsa, and elaborated by the Department of Water Resources of the National University of Athens. The authors are grateful to Prof. C. Green and an anonymous reviewer for their encouraging comments, which were also very helpful in rewriting several parts of the paper and making an improved presentation.

Edited by: P. van der Zaag

\section{References}

Agrell, P., Lence, B. J., and Stam, A.: An interactive multicriteria decision model for multipurpose reservoir management: the Shellmouth reservoir, J. Multi-Crit. Decis. Anal., 7, 61-86, 1998.

Andreadakis, A., Noutsopoulos, C., and Gavalaki, E.: Assessment of the water quality of Lake Plastira through mathematical modelling for alternative management scenarios, in Proceedings of the 8th International Conference on Environmental Science and Technology, Lemnos Island, Greece, 2003.

Arler, F.: Aspects of landscape or nature quality, Landscape Ecol., 15, 291-302, 2000.

Bonte, R. J., Janssen, R., Mooren, R. H. J., d. Smidt, J. T., and v. d. Burg, J. J.: Multicriteria analysis: making subjectivity explicit, in Experiences on Environmental Impact Assessment in the Netherlands: Process, Methodology, Case Studies, 23-28, 1998. 
Cohon, J. L.: Multiobjective programming and planning, Academic Press, 1978.

Dreyfus, H. L. and Dreyfus, S.: Mind Over Machine: The Power of Human Intuition and Expertise in the Era of the Computer, Free Press, 1986.

Easen, P. and Wilcockson, J.: Intuition and rational decisionmaking in professional thinking: a false dichotomy?, J. Adv. Nurs., 24, 667-673, 1996.

Hadjibiros, K., Koutsoyiannis, D., Katsiri, A., Stamou, A., Andreadakis, A., Sargentis, G.-F., Christofides, A., Efstratiadis, A., and Valassopoulos, A.: Management of water quality of the Plastiras reservoir, in 4th International Conference on reservoir limnology and water quality, Ceske Budejovice, Czech Republic, 2002

Hadjistathis, A. and Ispikoudis, I.: Prostasia tis fisis kai architektoniki tou topiou (Protection of nature and landscape architecture), Yachoudi-Yapouli OE, Thessaloniki, 1995.

Hipel, K. W.: Multiple objective decision making in water resources, Water Resour. Bull., 28, 3-12, 1992.

Koutsoyiannis, D.: A generalised mathematical framework for stochastic simulation and forecast of hydrologic time series, Water Resour. Res., 36(6), 1519-1534, 2000.

Koutsoyiannis, D.: Reliability concepts in reservoir design, in: The Encyclopedia of Water, edited by: Lehr, J. H., Wiley, 2004.

Loomis, J. and Feldman, M.: Estimating the benefits of maintaining adequate lake levels to homeowners using the hedonic property method, Water Resour. Res., 39(9), 2.1 to 2.6, 2003.

Loucks, D. P., Stedinger, J. R., and Haith, D. A.: Water Resource Systems Planning and Analysis, Prentice Hall, 1981.

Mays, L. W. and Tung, Y. K.: Systems analysis, in Water Resources Handbook, McGraw-Hill, 1996.

Mas-Colell, A., Whinston, M. D., and Green, J. R.: Microeconomic theory, Oxford University Press, 1995.

Moore, G. A.: Crossing the chasm: Marketing and selling technology products to mainstream customers, Capstone Publishing, second edition edn., 1999.
Nebel, B. J. and Wright, R. T.: Environmental Science, Prentice Hall, 1981.

Neto, F.: A new approach to sustainable tourism development: Moving beyond environmental protection, Nat. Resour. Forum, 27, 212-222, 2003.

Pegram, G. G. S.: On reservoir reliability, J. Hydrol., 47, 269-296, 1980.

ReVelle, C.: Optimizing Reservoir Resources, John Wiley \& Sons, 1999.

Rosen, S.: Hedonic prices and implicit markets: Product differentiation in pure competition, J. Polit. Econ., 82, 34-55, 1974.

Sargentis, G.-F.: To aisthitiko stichio sto nero, ta ydravlika erga kai ta fragmata (The aesthetical element in water, hydraulic works and dams), Diploma thesis, National Technical University of Athens, Department of Water Resources, Hydraulic and Maritime Engineering, 1998.

Sargentis, G.-F., Hadjibiros, K., and Christofides, A.: Plastiras lake: the impact of water level on the aesthetic value of the landscape, in Proceedings of the 9th International Conference on Environmental Science and Technology, Rhodes, Greece, 2005.

Stamou, A. I., Christodoulou, G. C., and Petroulas, M.: Modeling of pollution in coastal areas, in Proceedings of the International Conference for the Restoration and Protection of the Environment II, Patras, Greece, 1994.

Stefanou, I.: I fisiognomia enos topou: o charaktiras tis ellinikis polis ton 210 aiona (The physiognomy of a place: the character of the Greek town in the 21st century), National Technical University of Athens and Ministry of Environment, City Planning, and Public Works, Athens, 2001.

Wenstøp, F. and Seip, K.: Legitimacy and quality of multi-criteria environmental policy analysis: a meta analysis of five MCE studies in Norway, J. Multi-Crit. Decis. Anal., 10, 53-64, 2001.

Wierzbicki, A. P.: On the role of intuition in decision making and some ways of multicriteria aid of intuition, J. Multi-Crit. Decis. Anal., 6, 65-76, 1997. 